\title{
Sensitive detection of Escherichia coli 0157:H7 based on cascade signal amplification in ELISA
}

\author{
Shan Shan, ${ }^{*}$ Daofeng Liu,† Qi Guo, ${ }^{*}$ Songsong Wu, ${ }^{*}$ Rui Chen, ${ }^{*}$ Kai Luo, ${ }^{*}$ Liming Hu, ${ }^{*}$ Yonghua Xiong, ${ }^{*}$ \\ and Weihua Lai ${ }^{* 1}$ \\ *State Key Laboratory of Food Science and Technology, Nanchang University, Nanchang 330047, China \\ †Jiangxi Province Centers for Disease Control and Prevention, Nanchang 330096, China
}

\section{ABSTRACT}

In this study, cascade signal amplification in ELISA involving double-antibody sandwich ELISA and indirectly competitive ELISA was established to sensitively detect Escherichia coli O157:H7. In the double-antibody sandwich ELISA, a complex was formed comprising anti-E. coli O157:H7 polyclonal antibody, E. coli O157:H7, biotinylated anti-E. coli O157:H7 monoclonal antibody, streptavidin, and biotinylated $\beta$-lactamase. Penicillin solution was then added into the ELISA well and hydrolyzed by $\beta$-lactamase. Afterward, the penicillin solution was transferred to indirectly competitive ELISA. The concentration of penicillin can be sensitively detected in indirectly competitive ELISA. In the cascade signal amplification system, increasing the amount of added E. coli O157:H7 resulted in more $\beta$-lactamase and less penicillin. The detection sensitivity of E. coli O157:H7, which was $20 \mathrm{cfu} / \mathrm{mL}$ with the cascade signal amplification in ELISA, was 1,000-fold higher than that of traditional ELISA. Furthermore, the novel method can be used to detect E. coli O157:H7 in milk $(2 \mathrm{cfu} / \mathrm{g})$. Therefore, this new signaling strategy will facilitate analyses of highly sensitive foodborne pathogens.

Key words: Escherichia coli O157:H7, signal amplification, ELISA, milk

\section{INTRODUCTION}

Foodborne disease caused by pathogens is a major public health issue worldwide. Approximately 600 million people fall ill after eating contaminated food, of which 420,000 die every year, resulting in the loss of 33 million healthy life years. Diarrheal diseases are among the most common of such illnesses, causing 550 million

Received April 14, 2016.

Accepted May 25, 2016.

${ }^{1}$ Corresponding author: talktolaiwh@163.com people to fall ill and leading to 230,000 deaths every year (WHO, 2015). Escherichia coli O157:H7 is one of the most common foodborne pathogens affecting millions of people annually - sometimes with severe and fatal outcomes. The traditional method for detection of pathogens is time-consuming and laborious. Rapid detection methods of foodborne pathogens with high sensitivity are essential for disease prevention and public safety. To detect foodborne pathogens, some methodologies have been developed, including PCR (Sjöling et al., 2015; Xu et al., 2016), microfluidic device (Tian et al., 2016), electrochemical strategies (Su et al., 2011), biosensors (Yamada et al., 2016), and array-based detection methods (Charlermroj et al., 2014; Zhang et al., 2015). These methods can sensitively identify foodborne pathogens, but they require skill and facilities.

Enzyme-linked immunosorbent assay, which is fast, simple, cheap, and requiring few skills, has been used extensively as a diagnostic tool in laboratory and clinical analyses (Qu et al., 2014). Enzymes are a group of biological macromolecules, generally referred to as proteins with high catalytic activity, selectivity, and specificity. The characteristics of enzymatic reaction can be described as follows: (1) enzymes accelerate chemical reaction and the quality and quantity of enzymes do not change before and after the reaction; (2) enzymes demonstrate high catalytic efficiency; and (3) enzymes also present high specificity. Traditional ELISA employs enzyme catalytic substrates generating colored molecules as signal reporters. However, one limitation of traditional ELISA using enzyme-antibody conjugates as labels is its relatively low sensitivity. To solve this problem, efforts have been made to improve detection sensitivity by combining with PCR (Malou and Raoult, 2011), introducing biotin-streptavidin systems (Gould et al., 1985) and enzyme-loaded particles (Qu et al., 2014; Chen et al., 2015), or improving the specific activity of enzyme labels (Haupt et al., 2005). Some researchers have used alternative approaches to change signal readout based on totally different signaling principles (Amani et al., 2015; Zhu et al., 2015). It 
is beneficial to choose an appropriate signal readout mode for the signal amplification in ELISA.

Two kinds of ELISA, namely, double-antibody sandwich ELISA (ds-ELISA) and indirectly competitive ELISA (ic-ELISA), were integrated to establish a cascade signal amplification system in the current study. In the novel system, increasing the amount of added E. coli O157:H7 resulted in more $\beta$-lactamase and less penicillin. The concentration of $E$. coli $\mathrm{O} 157: \mathrm{H} 7$ can be detected sensitively by determining the concentration of penicillin.

\section{MATERIALS AND METHODS}

\section{Materials}

Sulfosuccinimidyl-6-[biotin-amido] hexanoate and streptavidin were obtained from Thermo Fisher Scientific Inc. (Waltham, MA). $\beta$-Lactamase (EC 3.5.2.6) and BSA were purchased from Aladdin Industrial Corporation (Shanghai, China). Penicillin was obtained from Shanghai Yuanye Bio-Technology Co., Ltd. (Shanghai, China). Murine anti-E. coli O157:H7 monoclonal antibody $(\mathbf{m A b})$ was prepared in our laboratory (Xiong et al., 2014). Goat anti-E. coli O157:H7 polyclonal antibody was purchased from Meridian Life Science Inc. (Memphis, TN). Penicillin receptor, penicillin-BSA, and anti-penicillin receptor $\mathrm{mAb}$ were purchased from Guangzhou Ucando Biotechnology Co. Ltd. (Guangzhou, China). Goat anti-mouse secondary antibodies labeled with horseradish peroxidase were purchased from Zhongshan Gold Bridge Biotechnology Co. Ltd. (Beijing, China). 2,2',5,5'-Tetramethylbenzidine enzyme substrate was purchased from Beijing Kewei Clinical Diagnostic Reagent Inc. (Beijing, China). See Supplemental Materials (http://dx.doi.org/10.3168/ jds.2016-11320) for additional methods.

\section{Bacteria and Culture Conditions}

Escherichia coli O157:H7 (ATCC 43888), E. coli (ATCC 25922), Salmonella Choleraesuis (ATCC 10708), Vibrio parahaemolyticus (CGMCC 1.1997), Staphylococcus aureus (CMCC 26003), Pseudomonas aeruginosa (CMCC 10104), Proteus vulgaris (CMCC 49027), Cronobacter sakazakii (CMCC 45001), Shigella sonnei (ATCC 25931), and Bacillus cereus (ATCC 14579) were cultured in Luria-Bertani medium (Oxoid, Basingstoke, UK) at $37^{\circ} \mathrm{C}$ for $12 \mathrm{~h}$ before use. Listeria monocytogenes (ATCC 13932) were cultivated with brain heart infusion (Becton, Dickinson and Company, Sparks, MD) at $37^{\circ} \mathrm{C}$ for $18 \mathrm{~h}$. Serial dilutions of cultures in PBS (0.01 $M, \mathrm{pH} 7.2)$ were produced and plated on trypticase soy agar (Becton, Dickinson and Company) to determine the number of viable cells. The plates were then incubated at $37^{\circ} \mathrm{C}$ for $24 \mathrm{~h}$. All the microbiology and analytical procedures were carried out under biosafety level 2 conditions.

\section{ds-ELISA Procedure}

The wells of each ELISA plate (Corning Inc., Corning, NY) were coated with $100 \mu \mathrm{L}$ of anti-E. coli O157:H7 polyclonal antibodies $(5 \mu \mathrm{g} / \mathrm{mL})$ overnight at $4^{\circ} \mathrm{C}$. Plates were washed 3 times with $300 \mu \mathrm{L}$ of PBST (PBS containing $0.01 \%$ Tween 20). Subsequently, the plates were blocked with $300 \mu \mathrm{L}$ of $3 \%$ BSA in PBS (pH 7.4) for $1 \mathrm{~h}$ at $37^{\circ} \mathrm{C}$ and then washed 3 times with PBST. One hundred microliters of the sample was added to each well for $1 \mathrm{~h}$ at $37^{\circ} \mathrm{C}$ and then washed 3 times with PBST. One hundred microliters of biotinylated anti- $E$. coli $\mathrm{O} 157: \mathrm{H} 7 \mathrm{mAb}(10 \mu \mathrm{g} / \mathrm{mL}, \mathrm{S} 1.1)$ was added to each well for $1 \mathrm{~h}$ at $37^{\circ} \mathrm{C}$ and then washed 3 times with PBST. Furthermore, $100 \mu \mathrm{L}$ of streptavidin was added to each well for $1 \mathrm{~h}$ at $37^{\circ} \mathrm{C}$ and then washed 3 times with PBST. One hundred microliters of biotinylated $\beta$-lactamase (S1.1) was also added to each well for 1 $\mathrm{h}$ at $37^{\circ} \mathrm{C}$ and then washed 4 times with PBS. Finally, $100 \mu \mathrm{L}$ of penicillin $(1 \mathrm{ng} / \mathrm{mL}$ in PBS) was added to each well at $37^{\circ} \mathrm{C}$. Then, $50 \mu \mathrm{L}$ of penicillin hydrolysate was directly detected by ic-ELISA. All experiments were performed in triplicate.

\section{ic-ELISA Detection}

The wells of each ELISA plate were coated with 100 $\mu \mathrm{L}$ of $0.05 \mu \mathrm{g} / \mathrm{mL}$ penicillin-BSA overnight at $4^{\circ} \mathrm{C}$. Plates were washed 3 times with $300 \mu \mathrm{L}$ of PBST. The remaining protein-binding sites on the plates were blocked with $300 \mu \mathrm{L}$ of $3 \%$ BSA in PBS (pH 7.4) at $37^{\circ} \mathrm{C}$ for $1 \mathrm{~h}$. Fifty microliters of penicillin or penicillin hydrolysate (hydrolyzed by biotinylated $\beta$-lactamase and $50 \mu \mathrm{L}$ of $0.05 \mu \mathrm{g} / \mathrm{mL}$ penicillin receptor) was added to each well, incubated at $37^{\circ} \mathrm{C}$ for $1 \mathrm{~h}$, and then washed 3 times with PBST. Moreover, $100 \mu \mathrm{L}$ of $0.05 \mu \mathrm{g} / \mathrm{mL}$ anti-penicillin receptor was added to each well at $37^{\circ} \mathrm{C}$ for $30 \mathrm{~min}$ and then washed 3 times with PBST. One hundred microliters of goat anti-mouse secondary antibodies labeled with horseradish peroxidase $(1: 5,000$ in PBS) was also added to each well at $37^{\circ} \mathrm{C}$ for $30 \mathrm{~min}$ and then washed 6 times with PBST. One hundred microliters of $2,2^{\prime}, 5,5^{\prime}$-tetramethylbenzidine enzyme substrate was added at $37^{\circ} \mathrm{C}$ for $10 \mathrm{~min}$, and color development was stopped by adding $2 M$ sulfuric acid (50 $\mu \mathrm{L})$. The absorbance at $450 \mathrm{~nm}$ was measured using 
a microplate reader (Beijing Perlong New Technology Co. Ltd., Beijing, China). When $1 \mathrm{ng} / \mathrm{mL}$ of penicillin was detected by the ic-ELISA, the absorbance was $\mathbf{B}_{0}$; when $1 \mathrm{ng} / \mathrm{mL}$ of penicillin was partially hydrolyzed by $\beta$-lactamase and detected by the ic-ELISA, the absorbance was $\mathbf{B}$.

\section{Optimization of Streptavidin Concentration}

One hundred microliters of E. coli O157:H7 $\left(2 \times 10^{6}\right.$ $\mathrm{cfu} / \mathrm{mL}$ ) was selected as sample for detection. A total of $100 \mu \mathrm{L}$ of streptavidin at different concentrations $(0.5,1,3,5$, and $10 \mu \mathrm{g} / \mathrm{mL})$ was optimized. Ten micrograms per milliliter of biotinylated $\beta$-lactamase was also added. Up to $100 \mu \mathrm{L}$ of penicillin $(1 \mathrm{ng} / \mathrm{mL}$ in PBS, $\mathrm{pH}$ 7.0) was added to each well and incubated at $37^{\circ} \mathrm{C}$ for $60 \mathrm{~min}$. Finally, $50 \mu \mathrm{L}$ of penicillin hydrolysate was transferred into ic-ELISA for further detection.

\section{Optimization of $\beta$-Lactamase Concentration}

One hundred microliters of optimal streptavidin was added to each well, and $100 \mu \mathrm{L}$ of biotinylated $\beta$-lactamase at different concentrations $(0.5,1,3,5,10$, and $20 \mu \mathrm{g} / \mathrm{mL}$ ) was added. One hundred microliters of penicillin ( $1 \mathrm{ng} / \mathrm{mL}$ in PBS, $\mathrm{pH} 7.0)$ was added to each well and incubated at $37^{\circ} \mathrm{C}$ for $60 \mathrm{~min}$. Finally, $50 \mu \mathrm{L}$ of penicillin hydrolysate was transferred into ic-ELISA for further detection.

\section{Optimizing pH of Penicillin Solution}

One hundred microliters of optimal streptavidin and biotinylated $\beta$-lactamase was added to each well. A total of $100 \mu \mathrm{L}$ of penicillin solution $(1 \mathrm{ng} / \mathrm{mL})$, which was dissolved in PBS at different $\mathrm{pH}$ values $(4,5,6,7$, 8,9 , and 10), was added to each well and incubated at $37^{\circ} \mathrm{C}$ for $60 \mathrm{~min}$. Finally, $50 \mu \mathrm{L}$ of penicillin hydrolysate was transferred into ic-ELISA for further detection. As a control sample, $50 \mu \mathrm{L}$ of penicillin solution $(1 \mathrm{ng} / \mathrm{mL})$ at different $\mathrm{PBS} \mathrm{pH}$ values $(4,5,6,7,8,9$, and 10) was directly detected by ic-ELISA.

\section{Kinetics Analysis of the Hydrolysis Procedure}

Kinetics analysis of the hydrolysis procedure was performed as follows. One hundred microliters of optimal streptavidin and biotinylated $\beta$-lactamase was added to each well. Afterward, $100 \mu \mathrm{L}$ of penicillin solution was added to each well at $37^{\circ} \mathrm{C}$. Penicillin hydrolysate was directly detected by ic-ELISA at different reaction times $(10,20,30,45,60$, and $90 \mathrm{~min})$.

\section{Detection of E. coli 0157:H7}

Assessment in Pure Culture. Bacterial samples $\left(2 \times 10^{9} \mathrm{cfu} / \mathrm{mL}\right)$ were prepared by serial dilution in PBS to $2 \times 10^{8}, 2 \times 10^{7}, 2 \times 10^{6}, 2 \times 10^{5}, 2 \times 10^{4}, 2 \times$ $10^{3}, 2 \times 10^{2}, 2 \times 10$, and $2 \mathrm{cfu} / \mathrm{mL}$. The samples were detected by cascade signal amplification in ELISA.

Assessment in Whole Milk. Whole milk (3.25\% milk fat) was purchased from a local grocery store (Walmart, Nanchang, China) and tested as negative sample for E. coli O157:H7. Twenty-five grams of whole milk inoculated with $E$. coli $\mathrm{O} 157: \mathrm{H} 7$ at concentrations of $2 \mathrm{cfu} / \mathrm{g}$ was added into $225 \mathrm{~mL}$ of Luria-Bertani medium. The mixture was incubated at $37^{\circ} \mathrm{C}$ with gentle shaking at $180 \mathrm{rpm}$. Food samples were tested by cascade signal amplification in ELISA and colony counting after 5, 6, 7, 8, and $9 \mathrm{~h}$ (Wang et al., 2015).

Specificity Test. Escherichia coli O157:H7, E. coli, Salmonella Choleraesuis, Vibrio parahaemolyticus, Staphylococcus aureus, Pseudomonas aeruginosa, Proteus vulgaris, Cronobacter sakazakii, Shigella sonnei, Bacillus cereus, and Listeria monocytogenes (all were diluted to $10^{6} \mathrm{cfu} / \mathrm{mL}$ in PBS) were used to verify the specificity of the cascade signal amplification in ELISA.

\section{RESULTS AND DISCUSSION}

\section{Analytical Concept}

The overall detection scheme proposed in this study is depicted in Figure 1. The substrate in ds-ELISA is regarded as the analyst in ic-ELISA, the signal was amplified through a cascade ELISA system. The anti-E. coli $\mathrm{O} 157: \mathrm{H} 7$ polyclonal antibody was previously coated well in ELISA. Escherichia coli O157:H7 culture, biotinylated anti- $E$. coli $\mathrm{O} 157: \mathrm{H} 7 \mathrm{mAb}$, streptavidin, and biotinylated $\beta$-lactamase were added to the ELISA well consecutively. The more the amount of E. coli O157:H7 was increased, the more the $\beta$-lactamase was remained in ds-ELISA. Penicillin solution was then added into the ELISA well and hydrolyzed by $\beta$-lactamase when E. coli O157:H7 was added (Figure 1A). The concentration of penicillin remained unchanged when $E$. coli O157:H7 was not added (Figure 1B). Afterward, the penicillin solution was transferred to ic-ELISA. In icELISA, penicillin-BSA coated in the wells combined with the penicillin receptor when penicillin did not exist in the solution. Anti-penicillin receptor mouse antibody can bind specifically with penicillin receptor. Goat anti-mouse secondary antibody labeled with horseradish peroxidase bound with the anti-penicillin receptor mouse antibody. After adding the substrate solution, the color was measured by a microplate reader. In the 


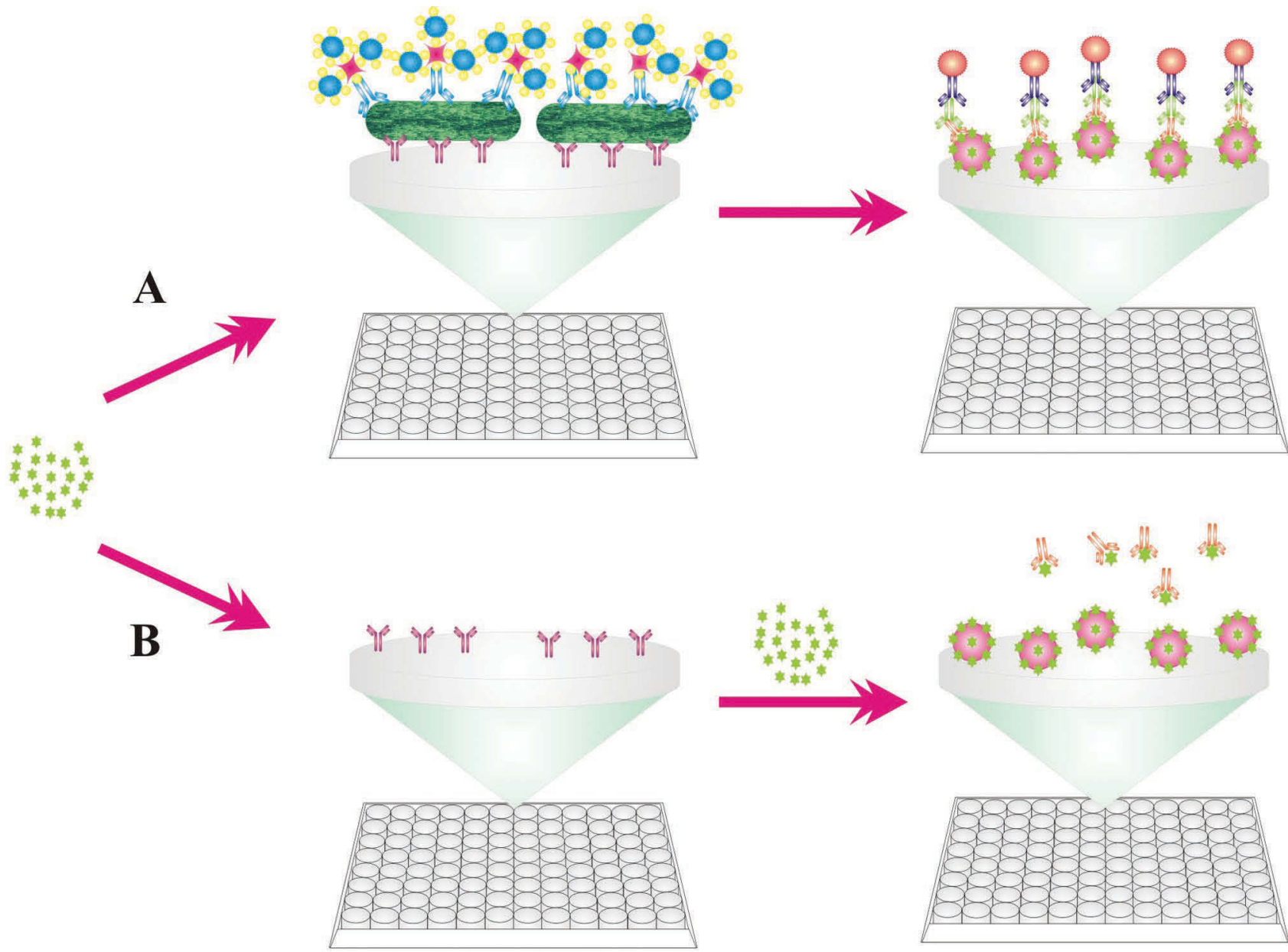

Anti-E. coli $0157:$ H7 polyclonal antibody

dt Penicillin receptor

Biotin

Anti-E. coli $0157:$ H7 monoclonal antibody

Anti-penicillin receptor mouse antibody
\&)

Goat anti-mouse secondary antibody-HRP

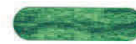

E. coli 0157: H7

\section{II}

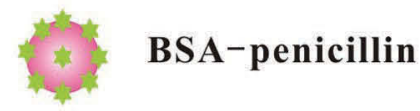

- $\beta$-lactamase

\section{Penicillin}

\section{Streptavidin}

Figure 1. Schematic of cascade signal amplification in ELISA. (A) Penicillin was added into well with Escherichia coli O157:H7; (B) penicillin was added into well without $E$. coli $\mathrm{O} 157: \mathrm{H} 7$. HRP $=$ horseradish peroxide.

cascade signal amplification system, when the amount of $E$. coli $\mathrm{O} 157: \mathrm{H} 7$ increased the amount of $\beta$-lactamase would increase and the penicillin content would de- crease. Thus, the concentration of E. coli O157:H7 can be detected sensitively by indirectly detecting the concentration of penicillin. 


\section{Optimization of Experimental Conditions}

When $1 \mathrm{ng} / \mathrm{mL}$ of penicillin was detected with icELISA, the absorbance of penicillin at $450 \mathrm{~nm}$ was $\mathrm{B}_{0}$. As shown in Figure 2, the absorbance of penicillin at $450 \mathrm{~nm}$ was 0.622 . With the increase in penicillin, the $\mathrm{B}-\mathrm{B}_{0}$ value decreased.

\section{Optimization of Streptavidin Concentration}

The concentration of streptavidin was important for detection sensitivity of the cascade signal amplification in ELISA. Low concentrations of streptavidin cannot accommodate enough biotinylated $\beta$-lactamase, thereby resulting in low sensitivity. By contrast, excessive amounts of streptavidin would promote nonspecific adsorption, resulting in high background noise. As shown in Figure 3, the signal-to-noise ratio was the highest at 20.22 when $5 \mu \mathrm{g} / \mathrm{mL}$ of streptavidin was added.

\section{Optimization of Biotinylated $\beta$-Lactamase Concentration}

The concentration of biotinylated $\beta$-lactamase was also a key factor for the detection sensitivity. The detection signal $\left(\mathrm{B}-\mathrm{B}_{0}\right)$ increased to 1.993 with $10 \mu \mathrm{g} /$ $\mathrm{mL}$ of biotinylated $\beta$-lactamase, and further addition of biotinylated $\beta$-lactamase did not significantly increase the $\mathrm{B}-\mathrm{B}_{0}$ (Figure 4 ).

\section{Optimizing pH of Penicillin Solution}

The $\mathrm{pH}$ of the solution affecting the detection system was studied. The results (Figure 5) showed that the

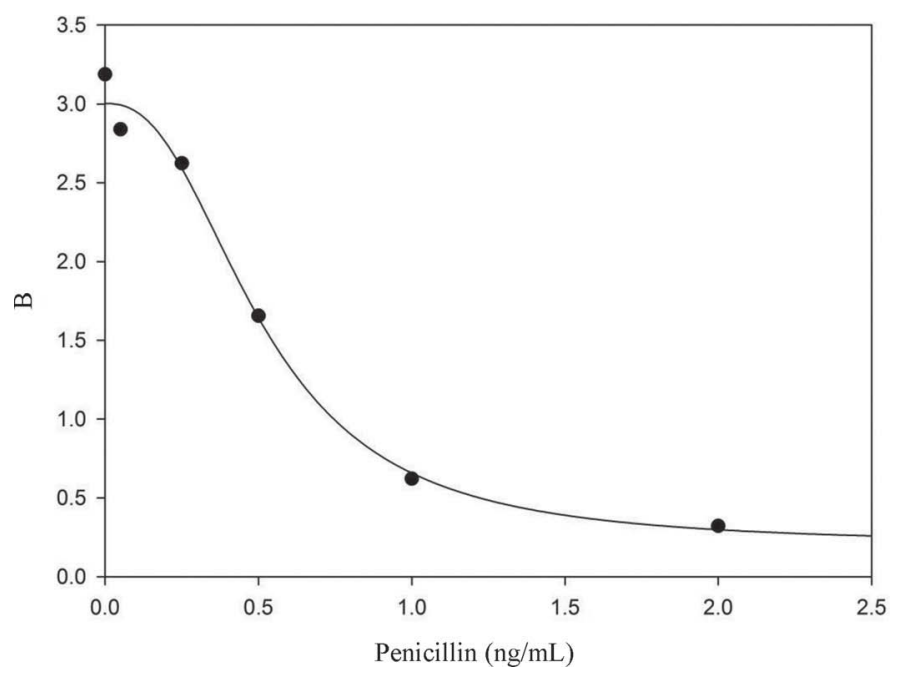

Figure 2. Detected sensitivity of penicillin by indirectly competitive ELISA.

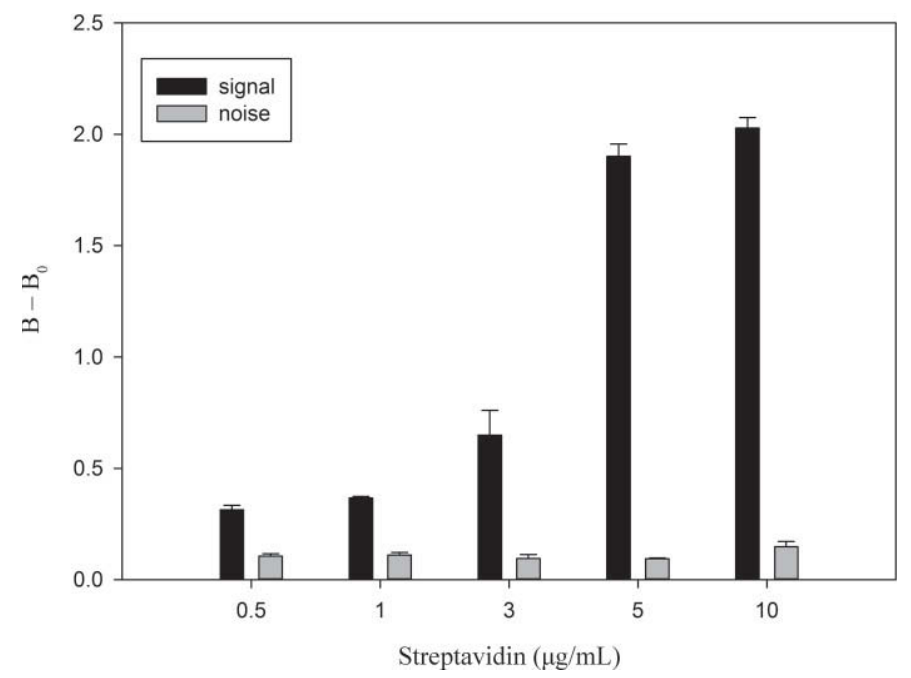

Figure 3. Effect of streptavidin concentration on the detection signal against $2 \times 10^{6} \mathrm{cfu} / \mathrm{mL}$ of Escherichia coli O157:H7. Signal represents the detection signal of $E$. coli $\mathrm{O} 157: \mathrm{H} 7$ by cascade signal amplification in ELISA with different concentrations of streptavidin, whereas noise represents the background noise of E. coli O157:H7 by cascade signal amplification in ELISA with different concentrations of streptavidin. Error bars indicate SD.

$\mathrm{pH}$ of the solution strongly influenced the activity of $\beta$-lactamase and penicillin. Penicillin can be hydrolyzed in both acidic and alkaline conditions without lactamase. These results agreed with previous reports (Bai and Zhang, 2013); thus, the $\mathrm{pH}$ of the solution in our study was set at 7.0.

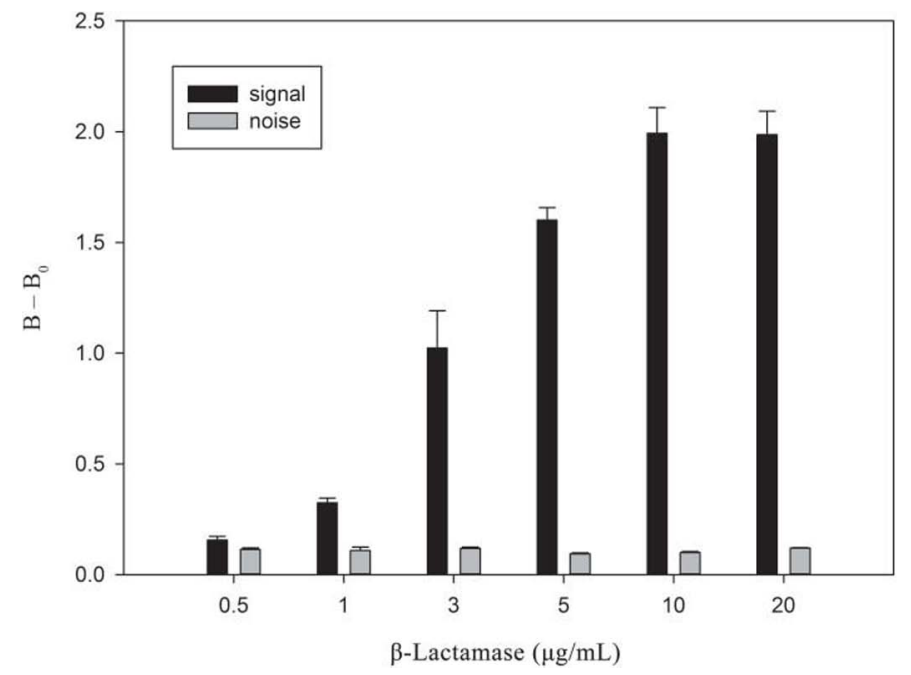

Figure 4. Effect of biotinylated $\beta$-lactamase concentration on the detection signal against $2 \times 10^{6} \mathrm{cfu} / \mathrm{mL}$ of Escherichia coli O157:H7. Signal represents the detection signal of E coli O157:H7 by cascade signal amplification in ELISA with different concentrations of biotinylated $\beta$-lactamase, whereas noise represents the background noise of $E$. coli O157:H7 by cascade signal amplification in ELISA with different concentrations of biotinylated $\beta$-lactamase. Error bars indicate SD. 


\section{Kinetics Analysis of the Hydrolysis Procedure}

Penicillin solution was added to the well containing $\beta$-lactamase. After different reaction times (10, 20, 30, 45, 60, and $90 \mathrm{~min}$ ), the penicillin hydrolysate was detected by ic-ELISA. The detection signal increased with a long reaction time. Penicillin can be hydrolyzed completely at $37^{\circ} \mathrm{C}$ for $60 \mathrm{~min}$ (Figure 6). To achieve the desired results and reduce the total processing time, 60 min was selected as the reaction time.

\section{Sensitivity Assessment}

Under the optimal conditions discussed above, the system was applied to quantitatively detect $E$. coli O157:H7 in PBS. The concentrations of E. coli O157:H7 ranged from 2 to $2 \times 10^{9} \mathrm{cfu} / \mathrm{mL}$, as shown in Figure 7. Usually, a threshold value was set to determine the detection limits based on the signal $\left(\mathrm{B}-\mathrm{B}_{0}\right)$, which can be calculated from the average signal intensity and standard deviation of the negative control (PBS). The threshold value, which was the total contribution of the average signal intensity and 3 times the standard deviation (average intensity $\pm 3 \mathrm{SD}$ ), was 0.167 . The corresponding concentration of E. coli O157:H7 can be regarded as the detection limit, when the detected optical value is larger than the threshold value. In our study, when the concentration of E. coli $\mathrm{O} 157: \mathrm{H} 7$ was $20 \mathrm{cfu} / \mathrm{mL}$, the signal was 0.288 . Thus, the detection limit of the cascade signal amplification in ELISA was $20 \mathrm{cfu} / \mathrm{mL}$. As shown in Figure 8, the detection limit of E. coli $\mathrm{O} 157: \mathrm{H} 7$ by traditional ELISA (S1.2.) was

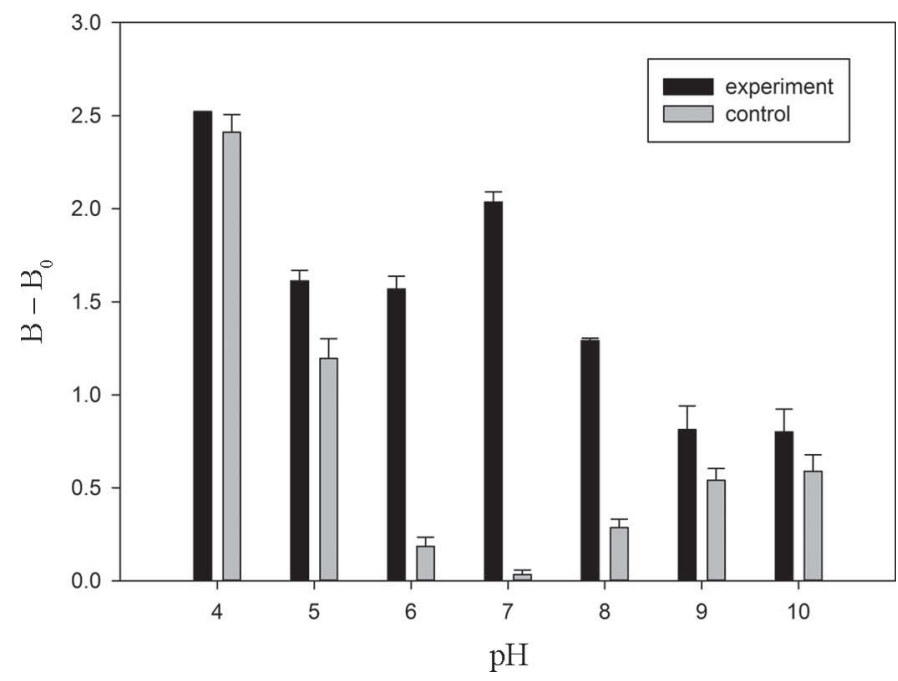

Figure 5. Effect of $\mathrm{pH}$ on detection signal. Experiment represents the detection signal of $1 \mathrm{ng} / \mathrm{mL}$ of penicillin with lactamase at different $\mathrm{pH}$ values of PBS; control represents the detection signal of $1 \mathrm{ng} /$ $\mathrm{mL}$ of penicillin at different $\mathrm{pH}$ values of PBS. Error bars indicate SD.

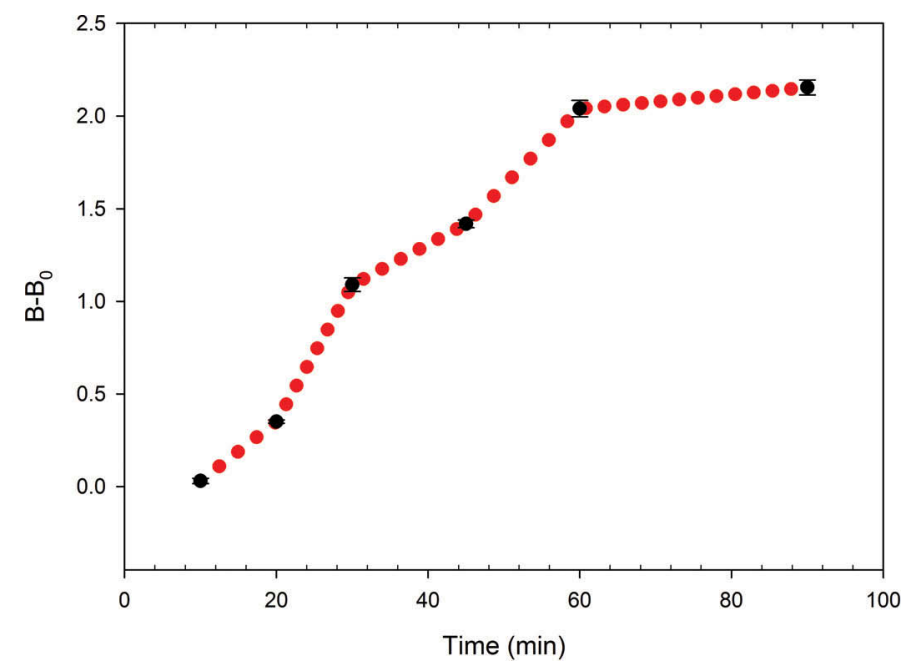

Figure 6. Hydrolysis dynamics of penicillin catalyzed by $\beta$-lactamase. Error bars indicate SD. Color version available online.

$2 \times 10^{4} \mathrm{cfu} / \mathrm{mL}$ (average intensity $\pm 3 \mathrm{SD}=0.42$ ). A 1,000-fold improvement in sensitivity was achieved by the cascade signal amplification in ELISA compared with traditional ELISA.

In the traditional ELISA detection system, the signal readout relies on optical-based measurements. Horseradish peroxide catalyzes the oxidation of hydrogen peroxide and chromogenic substrate. O-phenylenediamine, $2,2^{\prime}$-azino-bis (3-ethylbenzothiazoline-6-sulfonate), and $2,2^{\prime}, 5,5^{\prime}$-tetramethylbenzidine are among the most common chromogenic substrates. Chromogenic substrates require enough electrons from hydrogen peroxide to generate a colored solution. The cascade ELISA used the substrate (penicillin) of $\beta$-lactamase in ds-ELISA as

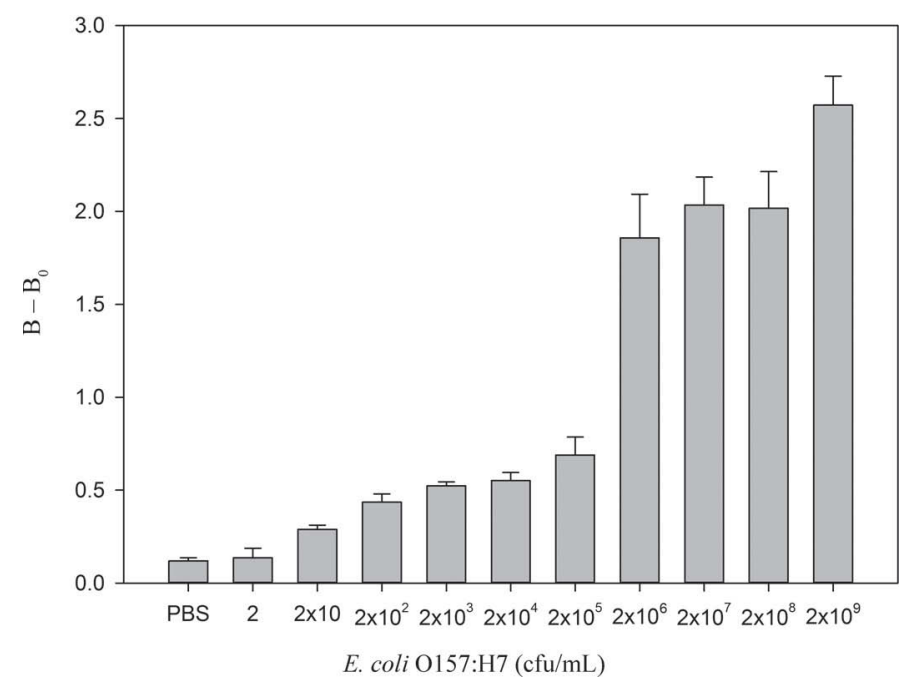

Figure 7. Detection sensitivity of Escherichia coli O157:H7 with cascade signal amplification in ELISA. Error bars indicate SD. 


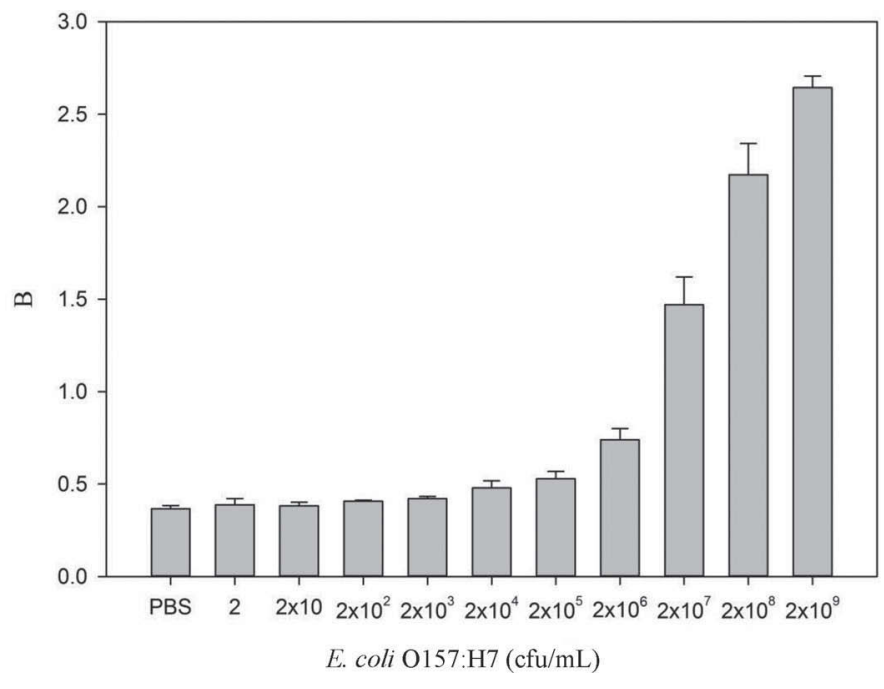

Figure 8. Detection sensitivity of Escherichia coli O157:H7 by traditional ELISA. Error bars indicate SD.

the target of ic-ELISA. The change in concentration of penicillin can be sensitively detected by ic-ELISA. High enzyme capacity was beneficial to signal amplification; the enzyme capacity was increased in the course of detection by the ds-ELISA. Thus, E. coli O157:H7 was ultrasensitive to detect, owing to optimization of the signal readout mode.

\section{Detection of E. coli 0157:H7 in Whole Milk}

The concentration of E. coli O157:H7 inoculated into milk was $2 \mathrm{cfu} / \mathrm{g}$. After $5 \mathrm{~h}$ of incubation, the milk

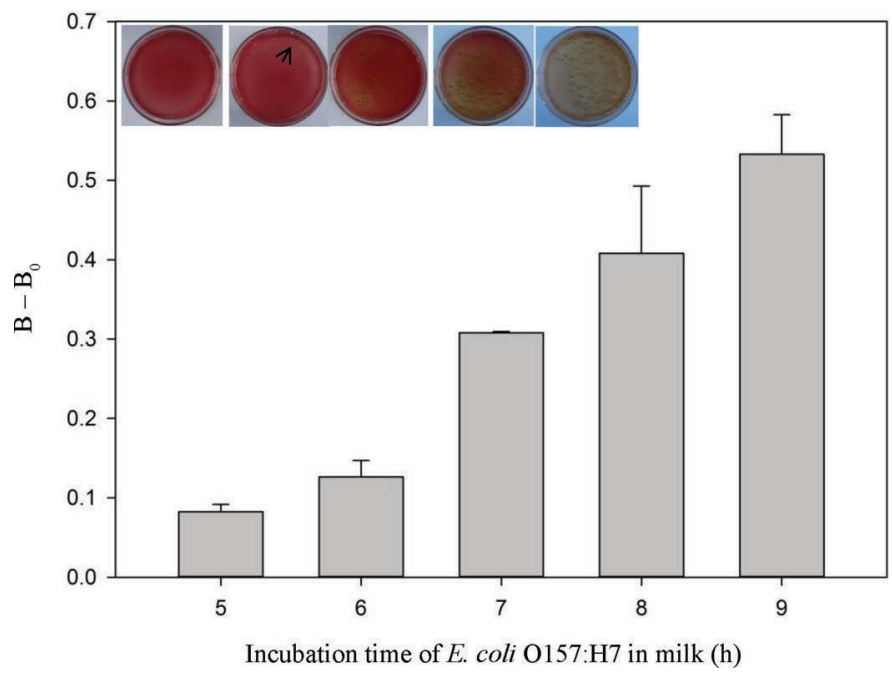

Figure 9. Optical signals of Escherichia coli O157:H7 in milk at different detection times with cascade signal amplification in ELISA. Error bars indicate SD. Color version available online. sample was tested using the cascade ELISA system for $1 \mathrm{~h}$. As shown in Figure 9, the time needed to detect E. coli $\mathrm{O} 157: \mathrm{H} 7$ in the spiked milk sample may reach up to $7 \mathrm{~h}$.

\section{Specificity Test with Selected Bacterial Strains}

When $10^{6} \mathrm{cfu} / \mathrm{mL}$ each of E. coli O157:H7, E. coli, Salmonella Choleraesuis, Vibrio parahaemolyticus, Staphylococcus aureus, Pseudomonas aeruginosa, Proteus vulgaris, Cronobacter sakazakii, Shigella sonnei, Bacillus cereus, and Listeria monocytogenes were detected by cascade signal amplification in ELISA, the $\mathrm{B}-\mathrm{B}_{0}$ of the 2 E. coli $\mathrm{O} 157: \mathrm{H} 7$ strains was 1.558 , and the $\mathrm{B}-\mathrm{B}_{0}$ of the other 10 bacteria were all lower than 0.18 (Figure 10). The results showed that the method exhibited sufficient specificity only with $E$. coli O157:H7 strains.

\section{CONCLUSIONS}

In this study, we successfully developed cascade signal amplification in ELISA for ultrasensitive detection of $E$. coli $\mathrm{O} 157: \mathrm{H} 7$. The sensitivity of the cascade signal amplification in ELISA for detecting E. coli O157:H7 was $20 \mathrm{cfu} / \mathrm{mL}$, which was 1,000 -fold higher than that of traditional ELISA. Furthermore, the novel method can be used to detect E. coli O157:H7 in whole milk.

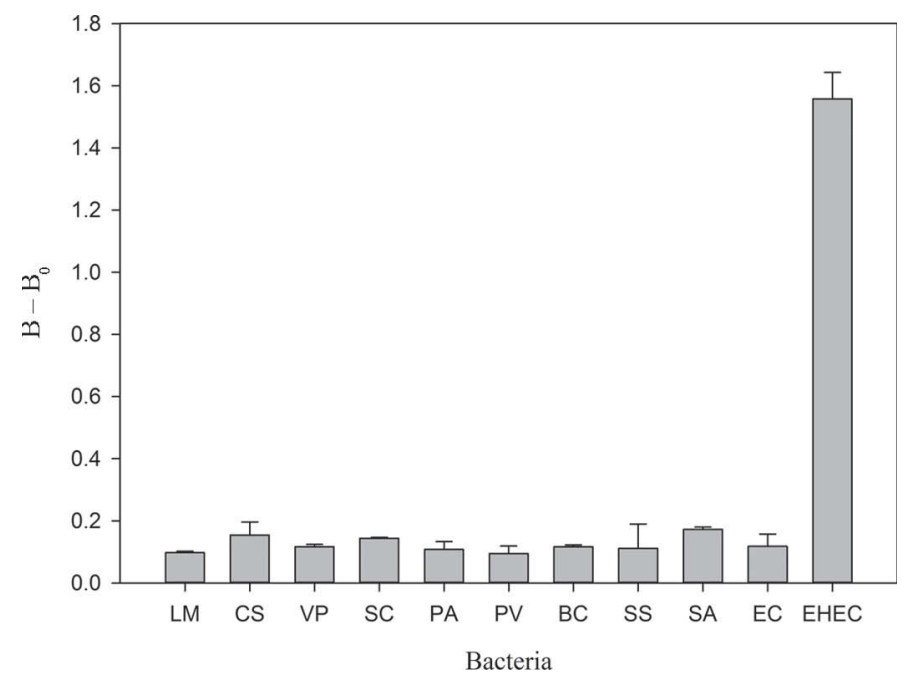

Figure 10. Specificity of cascade signal amplification in ELISA. $\mathrm{LM}=$ Listeria monocytogenes, $\mathrm{CS}=$ Cronobacter sakazakii, $\mathrm{VP}=$ Vibrio parahaemolyticus, $\mathrm{SC}=$ Salmonella Choleraesuis, $\mathrm{PA}=$ Proteus vulgaris, $\mathrm{PV}=$ Pseudomonas aeruginosa, $\mathrm{BC}=$ Bacillus cereus, $\mathrm{SS}=$ Shigella sonnei, $\mathrm{SA}=$ Staphylococcus aureus, $\mathrm{EC}=$ Escherichia coli, and $\mathrm{EHEC}=E$. coli $\mathrm{O} 157: \mathrm{H} 7$ (enterohemorrhagic E. coli). Error bars indicate $\mathrm{SD}$. 


\section{ACKNOWLEDGMENTS}

We are grateful to the Jiangxi Agriculture Research System (JXARS-03, Nanchang, China), and the Jiangxi Education Bureau Technology (project KJLD13009, Nanchang, China) for financial support.

\section{REFERENCES}

Amani, J., A. Ahmadpour, A. A. I. Fooladi, and S. Nazarian. 2015. Detection of E. coli O157:H7 and Shigella dysenteriae toxins in clinical samples by PCR-ELISA. Braz. J. Infect. Dis. 19:278-284.

Bai, Y., and C. Zhang. 2013. Thermal stability and acid resistance of penicillin in milk. China Diary 41:19-21. (In Chinese).

Charlermroj, R., O. Himananto, C. Seepiban, M. Kumpoosiri, N. Warin, O. Gajanandana, C. T. Elliott, and N. Karoonuthaisiri. 2014 Antibody array in a multiwell plate format for the sensitive and multiplexed detection of important plant pathogens. Anal. Chem. 86:7049-7056.

Chen, R., X. Huang, H. Xu, Y. Xiong, and Y. Li. 2015. Plasmonic enzyme-linked immunosorbent assay using nanospherical brushes as a catalase container for colorimetric detection of ultralow concentrations of Listeria monocytogenes. Appl. Mater. Interfaces 7:28632-28639. http://dx.doi.org/10.1021/acsami.5b10181.

Gould, E. A., A. Buckley, N. Cammack, and J. Virol. 1985. Use of the biotin-streptavidin interaction to improve flavivirus detection by immunofluorescence and ELISA tests. J. Virol. Methods 11:41-48.

Haupt, B., Th. Neumann, A. Wittemann, and M. Ballauff. 2005. Activity of enzymes immobilized in colloidal spherical polyelectrolyte brushes. Biomacromolecules 6:948-955.

Malou, N., and D. Raoult. 2011. Immuno-PCR: A promising ultrasensitive diagnostic method to detect antigens and antibodies. Trends Microbiol. 19:295-302.

Qu, Z., H. Xu, P. Xu, K. Chen, R. Mu, J. Fu, and H. Gu. 2014. An improved ultrasensitive enzyme-linked immunosorbent assay using hydrangea-like antibody-enzyme-inorganic three-in-one nanocomposites. Anal. Chem. 86:9367-9371.
Sjöling, Å., L. Sadeghipoorjahromi, D. Novak, and T. Joshua. 2015. Detection of major diarrheagenic bacterial pathogens by multiplex PCR panels. Microbiol. Res. 172:34-40.

Su, J., H. Zhang, B. Jiang, H. Zheng, Y. Chai, R. Yuan, and Y. Xiang. 2011. Dual signal amplification for highly sensitive electrochemical detection of uropathogens via enzyme-based catalytic target recycling. Biosens. Bioelectron. 29:184-188.

Tian, F., J. Lyu, J. Shi, F. Tan, and M. Yang. 2016. A polymeric microfluidic device integrated with nanoporous alumina membranes for simultaneous detection of multiple foodborne pathogens. Sens. Actuators B Chem. 225:312-318.

Wang, J. Y., M. H. Chen, Z. C. Sheng, D. F. Liu, S. S. Wu, and W. H. Lai. 2015. Development of colloidal gold immunochromatographic signal-amplifying system for ultrasensitive detection of Escherichia coli $\mathrm{O} 157: \mathrm{H7}$ in milk. RSC Advances 5:62300-62305.

World Health Organization. 2015. Food safety. Accessed December 2015. http://www.who.int/mediacentre/factsheets/fs399/en/

Xiong, Q., X. Cui, J. K. Saini, D. Liu, S. Shan, Y. Jin, and W. H. Lai. 2014. Development of an immunomagnetic separation method for efficient enrichment of Escherichia coli O157:H7. Food Contr. $37: 41-45$.

Xu, Y. G., Z. M. Liu, B. Q. Zhang, M. Qu, C. S. Mo, J. Luo, and S. L. Li. 2016. Development of a novel target-enriched multiplex PCR (Tem-PCR) assay for simultaneous detection of five foodborne pathogens. Food Contr. 64:54-59.

Yamada, K., W. Choi, I. Lee, B. K. Cho, and S. Jun. 2016. Rapid detection of multiple foodborne pathogens using a nanoparticlefunctionalized multi-junction biosensor. Biosens. Bioelectron. 77:137-143.

Zhang, H., Y. Zhang, Y. Lin, T. Liang, Z. Chen, J. Li, Z. Yue, J. Lv, Q. Jiang, and C. Yi. 2015. Ultrasensitive detection and rapid identification of multiple foodborne pathogens with the naked eyes. Biosens. Bioelectron. 71:186-193.

Zhu, Z., Z. Guan, D. Liu, S. Jia, J. Li, Z. Lei, S. Lin, T. Ji, Z. Tian, and C. J. Yang. 2015. Translating molecular recognition into a pressure signal to enable rapid, sensitive, and portable biomedical analysis. Angew. Chem. Int. Ed. 54:10448-10453. 